\title{
Archivos Argentinos de Pediatria: past, present, and perspectives
}

In September 2018, Archivos Argentinos de Pediatria was invited by the Collective Health Institute (Instituto de Salud Colectiva, ISCo) and the Portal of Scientific Journals of Universidad Nacional de Lanús, (UNLa) "Arturo Peña Lillo" to be part of the Second Symposium of Scientific Journals "Policies and practice in the digital era" held at Lanús, province of Buenos Aires, specifically to the panel discussion titled "Open access Argentine scientific journals and international circulation: difficulties, accomplishments, and challenges."

Revista de la Unión Matemática Argentina (Universidad Nacional del Sur, Bahía Blanca), Mundo Agrario (Universidad Nacional de La Plata), Quinto Sol (Historia, Universidad Nacional de La Pampa), and Archivos Argentinos de Pediatria were the journals invited to participate.

Each journal discussed part of their story, their journey to their present situation, and their future expectations.

The panel brought forth a very important opportunity to share-with the editors of the journals participating in the panel and representatives of journals from all over the country present in the audience and watching the live transmission- the problems common to all. These included carrying out exhaustive editorial work with limited human resources and materials, the need to professionalize the editorial process (e.g., with the use of new technologies), uninterrupted printing, publication sustainability, optimization of dissemination means, visibility and/or the impact of journal publication and the decision of some journals to be published only in English, to be indexed in different sites such as SciELO (currently with difficult access in Argentina), Scopus, Redalyc, etc., and the shortage of reviewers.

So, how could we present Archivos Argentinos de Pediatria at a panel of journals of such diverse topics? How could we showcase the work of our journal after more than 88 years of publication? Based on this experience, here we will share with our readers (who are also authors and reviewers) our most outstanding accomplishments, some aspects of our present, challenges, and perspectives.

We have seen significant successes in recent years, including:

In 2006, Archivos Argentinos de Pediatria was admitted to the SciELO database; in 2008, it was indexed in Medline by the United States National
Library of Medicine, without remarks. We have recently celebrated the $10^{\text {th }}$ anniversary of this historic milestone in the journal's existence.

In 2013, we started publishing original articles translated into English in our online version. This was actually a transcendental moment and, as expected back then, a before and an after in the journal's existence. Article dissemination has increased from year to year. This not only provided a space for the communication and dissemination of pediatric scientific projects conducted in Argentina and Ibero-America, but it also extended our universe of authors and readers to European and Asian countries.

In 2017, the volume of articles increased. We received 441 manuscripts for assessment; more than half of these were from abroad $(56 \%)$. The most contributing countries from Latin America included Chile, Colombia, Peru, and Venezuela; from North America, Mexico; from Europe, Spain; and from Asia, Turkey, which contributed one third of all articles from abroad. Recently, we have also received manuscripts from China and countries as far away as Nepal, Japan, and Malaysia.

At present, in addition to original articles, we have original brief reports, updates, special articles, editorials, and comments translated.

Six issues are published yearly; the printed version, in Spanish only, and the online version, in Spanish and English. With a print run of approximately 8000 copies, 210 articles were published in 2017.

The non-publication rate in 2017 was $45.6 \%$, and the main reasons for this were article quality and lack of response to suggested remarks.

Below you will find some of the most important news of the past year:

- As of September 2017, we started using the Open Journal Systems (OJS) platform for our manuscript review process.

- The number of original articles, special articles, and updates published online increased.

- We have also added the Supplement section (in electronic format), which includes the complete works of the Sociedad Argentina de Pediatria subcommittees, committees, and task forces. Each article is assigned a Digital Object Identifier (DOI) and is included in PubMed.

- In addition, the issues published between 1960 and 1979 are being digitized for their publication in our website. 


\section{Difficulties}

More than $50 \%$ of published articles undergo an editorial process of approximately 4-5 months since they are received until they are accepted for publication.

As is the case with practically all journals, those participating in the symposium and those located around the world, one of the greatest current difficulties is thematic peer review, either the lack of response and rejection to review a manuscript or the delays in review return.

Peer review is a time-consuming thorough task requiring effort and involvement. How could we maintain a functioning peer review system?

The Sociedad Argentina de Pediatria and Archivos Argentinos de Pediatria are continuously working to encourage reviewers. Credits per each review are granted for professional certification and revalidation in the field of pediatrics and other specialties. We also provide formal recognition by naming each national and international reviewer collaborating with the journal in the first issue of the following year. In addition, we offer a brief, free online course at the Sociedad Argentina de Pediatria website (virtual campus) titled "How to conduct a manuscript review" to encourage and support, above all, lessexperienced professionals. Besides, we provide instructions for reviewers in a guideline form which facilitates manuscript review.

Another aspect discussed with the other journals is how to maintain the open access model. The objective is to disseminate novel, relevant scientific knowledge and make it available for the entire scientific community and patients. This is possible, in part, thanks to the funds provided by universities and scientific organizations or societies, which help to sustain journal development. However, financial resources are finite and journals are progressively implementing new modalities, such as charging fees for editorial process initiation, translations or other contributions made by authors.

\section{Challenges and perspectives}

The large quantity of circulating information calls for the use of new technologies aimed at improving the editorial process, such as software to detect plagiarism.

In line with environment protection, Archivos Argentinos de Pediatria is in the process of shifting from print to electronic publishing; to this end, it is necessary to make the publication economically sustainable by funding the electronic version (e.g., through advertising).

Another concern is to give visibility as soon as possible to scientific production once approved for publication and before it is included in the contents of a specific issue. A resource to this end is to publish content online first, assign it a DOI, and even upload it to PubMed before its publication.

Archivos Argentinos de Pediatria is a dynamic publication that is constantly adapting to new challenges (using new technologies, increasing visibility, shortening publication deadlines, etc.) in order to offer a good-quality, scientifically rigorous, interesting journal. This is an accomplishment shared with our readers, authors, reviewers, and the entire editorial team, with the continuous support of the Sociedad Argentina de Pediatria authorities in such intense editorial journey.

As a brief final remark, I would like to quote a passage on Archivos Argentinos de Pediatria, from the book 100 years of the Sociedad Argentina de Pediatria (chapter 5):

Maintaining the scientific quality of published material, its frequency of publication, and the excellence conditions required by this space is an ongoing challenge for the entire pediatric community.

Adriana Aguilar Assistant Editor

http:/ / dx.doi.org/10.5546/ aap.2019.eng.2

To cite: Aguilar A. Archivos Argentinos de Pediatria: past, present, and perspectives. Arch Argent Pediatr 2019;117(1):2-3. 